\title{
Assessment of Adenosine Deaminase Level and the Utility of Polymerase Chain Reaction in Diagnosis of Tuberculous Pleural Effusion
}

\author{
Nagila $\mathbf{A}^{\mathbf{1}^{*}}$, Khanal $\mathrm{S}^{2}$, Dhakal $\mathrm{N}^{3}$, Bhatta $\mathrm{M}^{4}$, Tamrakar $\mathrm{BK}^{5}$ \\ ${ }^{1}$ Associate Professor, Department of Biochemistry, Gandaki Medical College \& Teaching Hospital, \\ Laboratory Chief, Fishtail Hospital and Research Center Pvt. Ltd., Pokhara, Nepal \\ ${ }^{2}$ Lecturer, Pokhara Bigyan Tatha Prabidhi Campus, Pokhara, Nepal \\ ${ }^{3}$ Lecturer, ${ }^{4}$ Assistant Professor, Department of Biochemistry, Gandaki Medical College \& Teaching Hospital, Pokhara, Nepal \\ ${ }^{5}$ Consultant Physician, Fishtail Hospital and Research Center Pvt. Ltd., Pokhara, Nepal
}

\author{
Keywords \\ Adenosine Deaminase, \\ Polymerase Chain Reaction, \\ Tubercular pleural effusion. \\ Corresponding author \\ Dr. Amar Nagila PhD Biochemistry \\ Associate Professor, Department of \\ Biochemistry \\ Gandaki Medical College \& Teaching \\ Hospital, Pokhara, Nepal \\ Email: nagila2a@gmail.com
}

\begin{abstract}
Background: Extrapulmonary tuberculosis is one of the major causes of exudative pleural effusion. The paucibacillary nature of effusion suggests the need of markers and methodologies for accurate diagnosis and prognosis of tuberculosis as well as to differentiate it from other non-tubercular causes of pleural effusion.
\end{abstract}

Objectives: This study was focused to evaluate the utility of polymerase chain reaction (PCR) in detection of tuberculosis antigen and to assess the level of Adenosine Deaminase (ADA) in tubercular pleural effusion (TPE) and contrast it with other causes.

Methods: This is a cross-sectional study where 100 samples of pleural effusion suspected to be tuberculosis were analyzed by PCR for the detection of IS6110 segment of DNA. The level of ADA was then determined and compared in both PCR positive and negative samples. The cut-off value of ADA was $>40 \mathrm{U} / \mathrm{L}$ for TPE. Student $\mathrm{t}$ test was applied to compare the means with statistical significance set at $\mathrm{p}<0.05$.

Results: Out of 100 samples analyzed, $45 \%$ were positive for TPE and remaining 55\% were non-tuberculous pleural effusion as detected by PCR. The level of ADA was above cut-off ( $>40 \mathrm{U} / \mathrm{L}$ ) in $43 \%$ TPE samples whereas all the non-tuberculous effusion had ADA $<40 \mathrm{U} / \mathrm{L}(\mathrm{p}<0.001)$.

Conclusion: The ADA level was significantly higher in TPE than in non-tuberculous cases, and PCR was able to detect suspected cases of tuberculous effusion in almost half of the cases. This findings suggests the diagnostic utility of combined use of ADA and PCR in diagnosis of TPE.

\section{INTRODUCTION}

Globally one third population carry the burden of tuberculosis (TB) and is a major public health problem with morbidity and mortality surpassing that of any other infectious disease. It is caused by Mycobacterium tuberculosis ${ }^{1}$. Nearly $85 \%$ of reported TB cases were limited to lungs with only $15 \%$ in extrapulmonary sites or both pulmonary and extrapulmonary sites ${ }^{2}$. Among this, pleural TB is commonly encountered extrapulmonary form, occurring in TB afflicted areas ${ }^{3}$. The common manifestation of extra-pulmonary TB is Tuberculosis Pleurisy (TP) which leads to pleural effusion. Examination of pleural fluid is therefore done for diagnosis of extrapulmonary TB infection ${ }^{4}$.

Pleural effusion resulting from tubercular infection is an exudative type $\mathrm{e}^{5}$ as a result of hypersensitivity reaction 
to mycobacteria and mycobacterial antigens in pleural space $^{6}$. Tuberculous pleural effusion characteristically presents with lymphocytosis and elevated adenosine deaminase (ADA) levels distinct from other types of pleural effusions ${ }^{7}$. Diagnosis of pleural TB is based on biochemical, microbiological and cytological analysis which has number of limitations ${ }^{8}$. However, measurement of Adenosine Deaminase enzyme in tubercular pleural fluid seems to be sensitive and reliable method as a diagnostic tool in high endemic TB areas, which is cheap and easy to form ${ }^{9,10}$. ADA in non tuberculous lymphocytic effusion rarely surpasses the cut off for tuberculous effusion ${ }^{11}$. Another quick method is Polymerase Chain Reaction (PCR) amplification method ${ }^{12}$ which is based on amplification of mycobacterial DNA fragments. As TB pleural effusion is paucibacillary disease, the sensitivity could be improved by PCR, as it can detect as few as 10 mycobacteria. However, PCR based methods are costly and pose a risk of contamination ${ }^{13}$.

In this study we aimed to differentiate pleural effusion as tuberculous and non-tuberculous using sensitive methodology of PCR and to compare the level of ADA activity in these tubercular and non-tubercular pleural effusions (NTPE).

\section{METHODS}

This is a cross-sectional comparative study conducted on patients with pleural effusion to rule out tubercular effusion from non-tubercular. This study was carried out from September 2016 to September 2017, in the Laboratory of Fishtail Hospital and Research Center Pvt. Ltd. Pokhara, Nepal. A total of 100 samples from patients of all age group who visited Fishtail Hospital and those who were suspected of having tubercular pleural effusion based of clinical findings were included in the study.

Samples collected aseptically in clean, sterile, leak proof vials and syringe with no visible signs of contamination, having proper label were accepted for analysis. Samples were aliquoted for ADA analysis and stored at $-20^{\circ} \mathrm{C}$ for PCR.

Pleural fluid samples were centrifuged at $3000 \mathrm{rpm}$ for 15 minutes, the supernatant was used for ADA examination whereas whole pleural fluid was stored and used for PCR analysis. ADA level was measured in supernatant by automated analyzer using ADAZYME enzymatic method. The cutoff value of pleural fluid ADA for the diagnosis of tubercular pleural effusion was $>40 \mathrm{U} / \mathrm{L}$ according to this method [Tulip Diagnostics (P) Ltd, INDIA] ${ }^{14}$. Values higher than cut-off were grouped under $>40 \mathrm{U} / \mathrm{L}$ whereas values less than cut-off were grouped under $<40 \mathrm{U} / \mathrm{L}$.

Extraction of DNA was done by CTAB (cetyl-trimethylammonium bromide)-phenol chloroform extraction method. IS6110 is an 1191-bp repetitive insertion sequence that is usually present 6-20 times in the M. tuberculosis complex genome. It is exclusively found in Mycobactrium tuberculosis complex (MTC) and thus has become important diagnostic tool for the identification of MTC species ${ }^{15}$. Amplification of DNA was performed with primers IS-F-5'-CCTGCGAGCGTAGGCGTCGG-3'and IS-R-5'-CTCGTCCAGCGCCGCTTCGG-3', to amplify $123 \mathrm{bp}$ fragment of insertion element IS6110 of M. tuberculosis complex.

PCR was carried out according to the standard protocol (provided by Fast-track reagent kit) The positive control included the DNA of H37Rv strain and negative control included PCR grade water. After PCR the amplified products were subjected to electrophoresis on a $2 \%$ agarose gel containing ethidium bromide and the results were recorded. The presence of $123 \mathrm{bp}$ fragment indicates the positive test for M. tuberculosis complex.

Data were entered on Microsoft Excel 2013 and were exported to Statistical Package for Social Sciences (SPSS) version 25 and analyzed. Student t-test was applied for comparison of means and a $p$ value $<0.05$ was deemed statistically significant. All the data were presented in the form of bar diagram in percentages.

\section{RESULTS}

Table 1 shows the demographic characteristics of cases enrolled for the study.

Table 1: Demographic characters of study subjects

\begin{tabular}{cccc}
\hline $\begin{array}{c}\text { Gender } \rightarrow \\
\text { Age group } \downarrow\end{array}$ & $\begin{array}{c}\text { Males } \\
\text { n (\%) }\end{array}$ & $\begin{array}{c}\text { Females } \\
\text { n (\%) }\end{array}$ & $\begin{array}{c}\text { Total } \\
\text { n (\%) }\end{array}$ \\
\hline$\leq 15 \mathrm{yrs}$ & $3(3 \%)$ & $2(2 \%)$ & $5(5 \%)$ \\
$16-45 \mathrm{yrs}$ & $49(49 \%)$ & $8(8 \%)$ & $57(57 \%)$ \\
$\geq 46 \mathrm{yrs}$ & $24(24 \%)$ & $14(14 \%)$ & $38(38 \%)$ \\
Total & $76(76 \%)$ & $24(24 \%)$ & $100(100 \%)$ \\
\hline
\end{tabular}

According to the table 1, there were more than three times the number of males (76\%) than females (24\%) and most of them were in their fifties (57\%) with only $5 \%$ of younger subjects with age less than 15 years. 
Figure 1 shows the percentage of positive and negative cases as detected by PCR. A total of 100 pleural effusions were taken in the study. Out of these, only 45 (45\%) samples were positive for tuberculosis and remaining 55 (55\%) samples were negative by PCR.

Fig 1: Cases classification by PCR

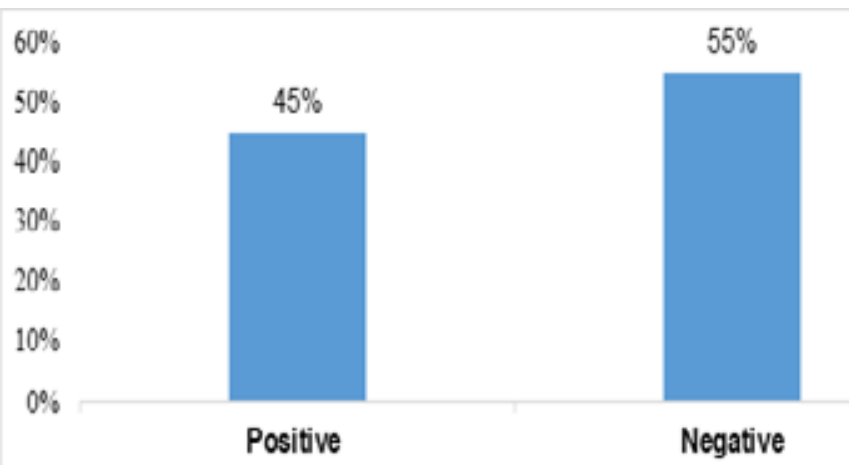

According to figure 2, the level of ADA was above the cutoff value of $40 \mathrm{IU} / \mathrm{L}$ in $43 \%$ of tubercular pleural effusion but was below $40 \mathrm{U} / \mathrm{L}$ in all NTPE $(\mathrm{p}<0.001)$. Only $2 \%$ of PCR positive cases had ADA level $<40 \mathrm{U} / \mathrm{L}$.

Fig 2: Pleural fluid ADA level in tubercular and nontubercular pleural effusion

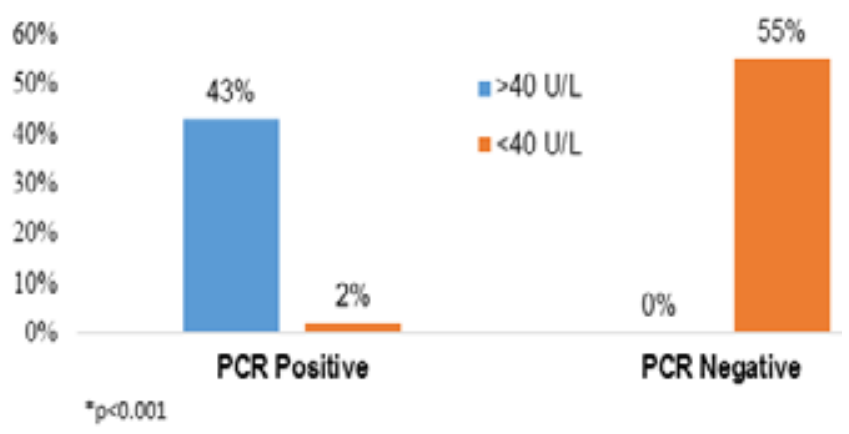

Table 2 compares the mean ADA level in tuberculous and non-tuberculous pleural fluid in different age groups.

Table 2: Age wise mean ADA level in tuberculous and non-tuberculous pleural fluid

\begin{tabular}{cccc}
\hline & \multicolumn{2}{c}{ Pleural Fluid ADA activity } & \\
\cline { 2 - 3 } Age (Years) & TPE $(\mathbf{n}=\mathbf{4 3})$ & $\begin{array}{c}\text { NTPE }(\mathbf{n}= \\
\text { 55) Mean }\end{array}$ & p-value \\
& Mean \pm SD & $\mathbf{\pm S D}$ & \\
\hline$\leq 15$ & $76.32 \pm 12.81$ & $15.32 \pm 9.92$ & $<0.001$ \\
$16-45$ & $125.21 \pm 34.32$ & $29.32 \pm 6.62$ & $<0.001$ \\
$\geq 46$ & $102.21 \pm 23.39$ & $19.29 \pm 8.93$ & $<0.001$ \\
Total average & $101.24 \pm 23.50$ & $21.31 \pm 8.49$ & $<0.001$ \\
\hline
\end{tabular}

According to figure 3, the mean ADA level in TPE (101.24 \pm 23.50 ) was significantly higher as compared to NTPE (21.31 \pm 8.49 ) with $p$ value $<0.001$. On the basis of age group, pleural fluid ADA was significantly higher in TPE in all three age groups as compared to their NTPE counterparts ( $\mathrm{p}<0.001$ for each age group).

\section{DISCUSSION}

Adenosine deaminase activity is elevated due to chronic antigenic stimulation of immune response as a result of cell mediated immunity (CMI) as seen in tuberculosis ${ }^{16}$. It is suggested that ADA has higher sensitivity than histopathological examination of pleural tissue for differential diagnosis of tubercular pleuritis because tuberculous pleurisy is a hypersensitivity reaction ${ }^{11}$. The use of PCR based test further enhances the sensitivity and specificity of diagnosis as it can detect small number of bacteria $^{17}$. For example, use of IS6110 which exclusively occur in Mycobactrium tuberculosis complex (MTC) and thus has become important diagnostic tool for the identification of MTC species ${ }^{15}$. Our study also showed more positive cases (45\%) of tubercular effusion by using IS6110 based PCR technique. Studies suggests that detection of IS6110 based PCR methods provides higher chance of detection of mycobacterial DNA in pleural fluid $^{18}$. Our study showed pleural effusions in PCR positive TPE cases with ADA level above cut-off value ( $>40 \mathrm{U} / \mathrm{L}$ ). This finding is supported by several other studies done by various authors in different time and places ${ }^{8,11,16,19,20}$ who have reported elevated ADA level in TPE cases than NTPE. From our study it can be reasoned that ADA can be used in differential diagnosis of tubercular pleural effusion form other types. Furthermore, the use of PCR in detection of mycobacteria from pleural effusion enhances detection. Thus, the combined used of PCR and ADA measurement can viewed to provide accuracy and exclude other cause of TPE.

The limitations of this study were that, we relied only on PCR and could not follow other diagnostic tools like culture and staining to find out specificity and sensitivity of methods. Large sample size and investigation of other biochemical markers could provide more information about the nature of pleural effusion which would help in establishing criteria for diagnosis of TPE. 


\section{CONCLUSIONS}

Hence, we found significantly high level of ADA in TPE than in non-tuberculous cases. The use of PCR helped to detect more tuberculous cases. In this context we recommend to use multiple tools for TB diagnosis in paucibacillary conditions like pleural effusion.

Acknowledgements: We acknowledge the support of Pokhara Bigyan Tatha Prabidhi Campus (PBPC) for providing the opportunity to complete this study. We are grateful to Dr. Amar Nagila and Mrs. Jyoti Chhetri for providing the necessary resources and guidance. I am also thankful to Mr. Hari Prasad Khanal (Campus chief, PBPC), Mr. Krishna Gurung (Lecturer, PBPC) and Prof. Dr. Bishnu Raj Tiwary (Pokhara University) for their constructive contribution.

\section{Source of Financial Support}

Pokhara Bigyan Tatha Prabidhi Campus, Fishtail Hospital and Research Center Pvt. Ltd.

\section{Conflicts of Interest}

All the authors declare that we have no any conflicts of interest

\section{REFERENCES}

1. Caulfield AJ, Wengenack NL. Diagnosis of active tuberculosis disease: From microscopy to molecular techniques. Journal of Clinical Tuberculosis and Other Mycobacterial Diseases. 2016; 4: 33-43.

2. Almazini MAI, Mankhia AA, Al-Kinani EAK. Study comparison of diagnostic methods for tuberculosis patients in Iraq. Advances in Bioresearch. 2015; 6(2).

3. Botianu PV, Botianu A-M. The Challenge of Diagnosing Pleural Tuberculosis Infection. Microbial pathogens and strategies for combating them: Science, technology and education: Formatex Research Center; 2013. p. $1950-6$.

4. Gui X, Xiao H. Diagnosis of tuberculosis pleurisy with adenosine deaminase (ADA): A systematic review and meta-analysis. International journal of clinical and experimental medicine. 2014; 7(10): 3126.

5. Chakrabarti B, Davies P. Pleural tuberculosis. Monaldi archives for chest disease. 2016; 65 (1).

6. Cohen LA, Light RW. Tuberculous Pleural Effusion. Turk Toraks Dergisi/Turkish Thoracic Journal. 2015;
$16(1)$

7. Kim CH, Lee SY, Lee YD, Yoo SS, Lee SY, Cha SI, et al. Atypical pleural fluid profiles in tuberculous pleural effusion: sequential changes compared with parapneumonic and malignant pleural effusions. Internal Medicine. 2016; 55(13): 1713-9.

8. Castro DJ, Nuevo GD, Perez-Rodriguez E, Light R. Diagnostic value of adenosine deaminase in nontuberculous lymphocytic pleural effusions. European Respiratory Journal. 2003; 21(2): 220-4.

9. Ghanei M, Aslani J, Bahrami H, Adhami H. Simple method for rapid diagnosis of tuberculosis pleuritis: A statistical approach. Asian Cardiovascular and Thoracic Annals. 2004; 12(1): 23-9.

10. Laniado-Laborin R. Adenosine deaminase in the diagnosis of tuberculous pleural effusion: is it really an ideal test? A word of caution. Chest. 2005; 127(2): 417-8.

11. Khushbu T, Lal GM. Evaluation of ADA activity in pleural fluid for tuberculous pleuritis. Journal of Contemporary Medical Research. 2016; 3(10): 3083-5.

12. Lima DM, Colares JKB, Da Fonseca BA. Combined use of the polymerase chain reaction and detection of adenosine deaminase activity on pleural fluid improves the rate of diagnosis of pleural tuberculosis. Chest. 2003; 124 (3): 909-14.

13. Gopi A, Madhavan SM, Sharma SK, Sahn SA. Diagnosis and treatment of tuberculous pleural effusion in 2006. Chest. 2007; 131(3): 880-9.

14. Diagnostics T. ADAZYME [Web page]. [cited 201822 April]. Available from: www.tulipgroup.com/Tulip_ New/html/product_specs/100_adazyme.html.

15. Coros A, DeConno E, Derbyshire KM. IS6110, a Mycobacterium tuberculosis complex-specific insertion sequence, is also present in the genome of Mycobacterium smegmatis, suggestive of lateral gene transfer among mycobacterial species. Journal of bacteriology. 2008; 190(9): 3408-10.

16. Lamsal M, Gautam N, Bhatta N, Majhi S, Baral N, Bhattacharya SK. Diagnostic utility of adenosine deaminase (ADA) activity in pleural fluid and serum of tuberculous and non-tuberculous respiratory disease patients. Southeast Asian J Trop Med Public Health. 2007 Mar; 38(2): 363-9. 
17. Chakravorty S, Sen MK, Tyagi JS. Diagnosis of extrapulmonary tuberculosis by smear, culture, and PCR using universal sample processing technology. Journal of Clinical Microbiology. 2005; 43(9): 435762.

18. de Lassence A, Lecossier D, Pierre C, Cadranel J, Stern $M$, Hance A. Detection of mycobacterial DNA in pleural fluid from patients with tuberculous pleurisy by means of the polymerase chain reaction: comparison of two protocols. Thorax. 1992; 47(4): 265-9.

19. Bhoumik S, Rahman M, Ibrahim M, Hiron M, Ahamad M. Evaluation of adenosine deaminase activity for diagnosis of tuberculous pleural effusion. Journal of Pathology of Nepal. 2013; 3(5): 367-73.

20. Verma S, Dubey A, Singh P, Tewerson S, Sharma D. Adenosine deaminase (ADA) level in tubercular pleural effusion. Lung India: Official Organ of Indian Chest Society. 2008; 25(3): 109. 